\title{
POR UMA LINGUAGEM MAIS HUMANA: COLETIVOS CIBERFEMINISTAS E CRÍTICAS À ABORDAGEM DAS MINORIAS EM NOTÍCIAS NA WEB
}

\author{
HELVIO DE ARAÚJO CALDEIRA JÚNIOR ${ }^{1}$ \\ LUÍZA MARTINS DOS SANTOS ${ }^{2}$ \\ STÉPHANI JÚLIA SALES LEITE ${ }^{3}$
}

Resumo: Como as mulheres tendem a ser representadas nos meios de comunicação? De que forma os recortes raciais, de gênero e de classe são evidenciados nas notícias? Quais são as consequências da má representação dos membros de comunidades marginalizadas para suas ascensóes sociais? Partindo de questốes como estas, o seguinte artigo se propõe a analisar notícias sobre mulheres e grupos minoritários veiculadas em portais populares, a fim de destacar como a linguagem pode colaborar para a manutenção de determinados estereótipos. Para isso, recorre ao fenômeno contemporâneo dos coletivos ciberfeministas de informação, sobretudo o portal brasileiro Think Olga e o projeto Minimanual do Jornalismo Humanizado, aplicando as recomendaçôes de comunicólogas feministas para o desenvolvimento de um discurso jornalístico que fomente mudanças sociais.

Palavras-chave: Comunicação; Mídia; Ciberfeminismo; Think Olga.

1 INTRODUÇÃO

Domingo, 13 de março de 2016. Dias após a data internacional em comemoração às mulheres, o portal de notícias Diário da Manhã publica uma reportagem ${ }^{4}$ sobre uma estudante de biologia brutalmente assassinada pelo namorado no laboratório da universidade. De

rais.

helviocald@gmail.com

2 Luíza Martins dos Santos é graduada em Jornalismo pela Universidade Federal de Minas Gerais. luiza5marsan@gmail.com

3 Stéphani Júlia Sales Leite é graduada em Jornalismo pela Universidade Federal de Minas Gerais. stephanijsales@gmail.com 
Por uma linguagem mais humana: coletivos ciberfeministas e críticas à abordagem das minorias em notícias na web

acordo com o texto, a vítima, de 20 anos, foi atraída para o local, imobilizada e obrigada a ina lar e beber clorofórmio, um composto químico mortal se ingerido. A partir daí, teve o corpo largado no laboratório pelo namorado, que saiu, voltou e cobriu o cadáver, o abandonando em um matagal em seguida. Em meio a descrições do ocorrido e depoimentos do culpado, o título da matéria parece chamar atenção. "Amor que mata”, diz o site.

Sexta-feira, 14 de dezembro de 2018. Dessa vez, é o $A$ Tribuna quem noticia ${ }^{5}$ a morte de mais uma mulher, em medida protetiva contra o então marido, que já a ameaçava de morte. Por meio das imagens de segurança, ficou comprovado que o assassino, armando-se de uma faca, atingiu a vítima próximo de onde trabalhava e fugiu. Ataques de fúria, crises de ciú me e comportamento agressivo são algumas das justificativas encontradas na reportagem, de nome "Marido matou esposa a facadas por ciúmes em Santos". A desconfiança ciumenta, assim, dá o tom de um texto que comprova: segundo a polícia, "marido matou esposa por ciúmes”.

No primeiro caso, uma emboscada na universidade. Já no segundo, a consequência da perseguição constante por parte de um marido. Mesmo distantes, as similaridades, no entanto, não se restringem só ao conteúdo, já que ambos são relativos à morte de mulheres por seus companheiros. Tanto na matéria do primeiro portal quanto no segundo, esfaqueamentos, agressóes e homicídios parecem, ainda que de modo sutil, atitudes justificadas com base em emoções afloradas. O sentimento de posse de homens em relação às suas mulheres, fruto da histórica misoginia, se transforma em um amor tão forte que leva ao descontrole.

Em um contexto no qual, de acordo com um estudo de 2017 da Comissão Econômica para a América Latina e o Caribe (Cepal), a cada dez feminicídios registrados em 23 países, quatro são do Brasil, a veiculação de narrativas do tipo parece no mínimo arriscada. Isso porque, ao orientarem reações sociais e comportamentais, é nítido que notícias possuem uma função maior que apenas "tornar as coisas vistas". Afinal, a depender da escolha das palavras, um texto revela preconceitos, destaca certos pontos ou os esconde, além de atuar na manutenção de certo imaginário sobre o mundo e as pessoas. No caso deste trabalho, nos interessa perceber o que o jornalismo diz sobre as minorias, entendidas como grupos em desvantagem dentro de uma sociedade. 
Para tal, partimos da ideia de notícia como forma de conhecimento de Robert Park, um dos grandes nomes da Escola de Chicago do início do século XX. Ao entendê-la enquanto algo que auxilia o ordenamento do corpo civil e seus valores, o pensador afirma que "a função da notícia é orientar o homem e a sociedade num mundo real” (PARK, 1976, p. 183). Ou seja: os textos de jornalistas, aqui, recebem o peso de mediar a relação dos sujeitos com o mundo. Com isso em mente, procuraremos analisar como as mulheres e demais grupos minoritários tendem a ser apresentados pelas notícias nos meios comunicativos. Com a visão de que a forma como se fala sobre as minorias influencia suas lutas por legitimidade social, utilizaremos como base para a análise as reivindicações promovidas pelo coletivo ciberfeminista Think Olga, que tem como objetivo promover o ativismo feminista por meio da informação. Assim, faremos dois movimentos: o primeiro tentando compreender as raízes de iniciativas jornalísticas formadas por mulheres na web, de forma contextualizada. No segundo, observaremos seus questionamentos sobre a representação de minorias pela mídia, o trabalho do Think Olga e a conseguinte aplicação de seus manuais em uma série de notícias.

\section{REFERENCIAL TEÓRICO}

\subsection{As mulheres e a imprensa brasileira}

A dificuldade de visualização clara das relações entre mulheres e jornalismo diz muito sobre sua participação na área ao longo dos anos. Embora haja um número cada vez maior de autores que se debrucem sobre o tema, é perceptível que este não é um terreno estável: há dúvidas sobre quando, de fato, as mulheres começaram a ocupar as bancadas e redações jornalísticas, assim como se o discurso dessas profissionais dizia respeito a pautas femininas ou políticas de esquerda mais amplas. Dessa forma, o compilado de informações deste trabalho pode ser considerado, mais que uma tentativa de demarcar e montar um panorama histórico, um esforço em reunir expoentes de destaque no ramo da chamada imprensa feminista no Brasil.

Tudo indica que o surgimento de uma imprensa direcionada exclusivamente aos interesses femininos teve seu ponto de partida no país na década de 1970, período este que marcou o movimento das mulheres em inúmeros países. Influenciadas por processos similares em outras nações, sobretudo as experiências europeias e norte-americanas, o feminismo brasileiro da época foi marcado pela união com outros movimentos populares e a contestação ao 
Por uma linguagem mais humana: coletivos ciberfeministas e críticas à abordagem das minorias em notícias na web

regime político vigente desde 1964. Embora possuísse características próprias, o movimento se ancorava a ideais marxistas e englobava também questionamentos gerais como reivindicaçốes estudantis e de classe, como Araújo (2000) faz questão de pontuar quando diz que se in sistia na especificidade e não na autonomia. É importante ressaltar, aqui, que as mulheres atuavam de forma clandestina devido às repressões do regime militar.

Nesse sentido, 1975 foi um divisor de águas para a legitimação feminista no território nacional, isso porque o ano foi declarado pela $\mathrm{ONU}$ como o Ano Internacional da $\mathrm{Mu}$ lher. A partir do decreto, que reconheceu o movimento e acabou criando terrenos formais para a luta das mulheres, observou-se a aparição pública de veículos destinados a denunciarem a hierarquia de gênero, tais quais o jornal Brasil Mulher (1975-1980) e Nós Mulheres (19761978). Interessante notar como a aparição dessas publicações diz respeito ao final do governo Médici, conhecido como o período de maiores operações repressivas, assim como grandes índices de desenvolvimento e estabilidade econômica na história do Brasil. Sugere-se, logo, certa relação entre a queda da violência e a progressiva expansão do sistema de ensino superior (que também englobava as mulheres) com a formalização da resistência das mulheres e sua presença no espaço público.

Enquanto narra as origens da imprensa feminista brasileira, Leite (2003) chama atenção para o fato de que

esses jornais, com formato tablóide e muitas vezes de tiragem irregular e circulação restrita, eram vendidos em bancas, porém a venda mais significativa ocorria no âmbito da militância. Tratava-se de uma imprensa com características de esquerda e de oposição ao regime, artesanal e comercializada, prioritariamente, mão a mão, ou seja, através da venda por militantes dos movimentos populares em eventos ou nas sedes das próprias organizaçóes (LEITE, 2003, s/p).

No caso do "Brasil Mulher", fundado em 1975 na cidade de Londrina, no Paraná, sua publicação acontecia pela Sociedade Brasil Mulher até 1980. Ao todo, foram 16 edições regulares e quatro "extras” que enfatizavam pautas como a reforma agrária, o uso de métodos anticoncepcionais e a entrada da mulher no mercado de trabalho, além de desafios da militância de esquerda e reivindicações à anistia para todas as pessoas que até então tinham sido perseguidas, presas e exiladas por conta de suas posiçóes políticas. A produção do periódico contava com um número de oito a trinta mulheres envolvidas. A tiragem era significativa para a época: com ampla circulação nacional, imprimia-se cerca de 5 a 10 mil exemplares de páginas em preto e branco e fotografias. Similarmente, o periódico "Nós Mulheres", editado 
pela Associação de Mulheres, teve oito edições e circulou por apenas dois anos — de 1967 a 1978. Suas militantes eram, em sua maioria, mulheres exiladas que voltaram ao Brasil com o propósito de editar um jornal feminista autônomo e independente. Quanto à relação entre as duas linhas editoriais e suas membras, Leite (2003) menciona que as constituintes do segundo

preferiram garantir sua 'autonomia', fundando um jornal próprio, o Nós Mulberes, a se integrar no já existente Brasil Mulher, reproduzindo, desse modo, a heterodoxia tão presente nas organizações de esquerda. O Brasil Mulher, por sua vez, temia as feministas que chegavam com muitas críticas à linha que havia adotado (LEITE, 2003, s/p).

Além destes, outra publicação que marcou a entrada feminina no espaço da Comunicação foi o jornal Mulherio, editado em 1981 pela Fundação Carlos Chagas com circulação até 1988. Dirigido pela jornalista Adélia Borges e com manutenção de um grupo de estudiosas da área, o veículo nasceu a partir do interesse de suas constituintes em estudar a condição da mulher no Brasil a partir de um viés mais acadêmico em Núcleos de Pesquisa em Estu dos da Mulher. Em sua análise sobre o jornal, Freitas (2014) explica que a distribuição era realizada entre órgãos de comunicação, grupos de mulheres, entidades culturais e acadêmicas. Com um conselho editorial formado por cerca de 16 mulheres, entre elas antropólogas e psiquiatras, seus textos (principalmente na fase embrionária do projeto) giravam em torno de questôes como a vida das mulheres no ambiente empresarial, a violência doméstica e, também, aspectos culturais como música, cinema e literatura. "A publicação se apresentava como o veículo que falaria sobre a mulher real, mulher em transformação, em movimento, não se colocando, novamente, como o porta-voz de nenhuma tendência do movimento político ou do movimento feminista” (FREITAS, 2014, p. 161).

As publicações são muitas e suscitam uma série de reflexóes, mas o que interessa aqui é observar como a eclosão dos primeiros periódicos dirigidos ao público feminino culminou na maior presença das mulheres em locais ocupados anteriormente apenas por homens. Além disso, vale destacar como suas reivindicaçôes também giravam em torno da mudança da linguagem jornalística no que diz respeito à forma como as mulheres eram retratadas pelos meios de comunicação. Ao direcionarem seus olhares para questóes específicas - e esquecidas - pelos veículos da esquerda da época, o que aquelas mulheres faziam é algo similar ao que se observa hoje com o surgimento de grandes coletivos ciberfeministas na web 2.0: empoderar por meio da informação. 
Por uma linguagem mais humana: coletivos ciberfeministas e críticas à abordagem das minorias em notícias na web

2.2 Ciberfeminismo: quarta onda do movimento?

Ao se estudar o movimento feminista, é muito comum se deparar com termos como "primeira onda" e "segunda onda", de forma que compreender as divisões do movimento pode ser essencial para demarcar certos pontos históricos e suas peculiaridades. Sem o risco de reduzir o tema, apresentamos abaixo o que se entende por ondas feministas - também tratadas como "fases feministas" a partir de suas particularidades.

Como primeira onda ${ }^{6}$, compreende-se o surgimento do movimento coletivo das mulheres durante o século XIX e XX, sobretudo em países como a França e a os Estados Unidos. O grande intuito, aqui, era a luta contra o preconceito sofrido pelas mulheres e a possibilidade de maiores direitos (algo que já tinha sido adquirido pelos homens), principalmente no que diz respeito ao voto. É importante ressaltar que, nesse primeiro momento, as mulheres que iam para as ruas para a reivindicação de seus direitos eram aquelas que ocupavam cargos hegemônicos na sociedade: brancas e de classe média. Questóes como a igualdade jurídica, voto e críticas à condução do casamento - normalmente, arranjado - eram algumas das pautas de destaque de suas representantes. Ou seja, o que importava nesse momento era conseguir um lugar na participação política e na vida pública, uma vez que o lugar designado para a mulher era o de dentro de casa.

Já a segunda onda diz respeito à movimentação das mulheres durante meados dos anos 50 até os anos 90 do século XX. Mais que direitos jurídicos, foi nesse contexto que começaram-se a questionar pontos como o controle da reprodução e da sexualidade feminina, além de protestos contínuos nas ruas contra a prostituição e a pornografia. Obras como "O Segundo Sexo", da francesa Simone de Beauvoir, ainda que publicadas antes da efervescência do movimento, se tornaram as grandes referências teóricas das mulheres que criticavam o sistema patriarcal. Há autores que definirão esse momento como aquele em que, de fato, há uma separação entre as noções de sexo e gênero: um enquanto característica biológica e outro como construção social. Como já mencionado, críticas à pornografia e à prostituição, assim como o matrimônio, o estupro e as demais violências sexuais podem ser descritas como principais pautas dessa segunda geração de feministas.

6 A noção de "primeira onda" foi cunhada pela primeira vez pela autora Marsha Lear para o periódico norteamericano The New York Times Magazine com o objetivo de diferenciar os objetivos de cada momento histórico no qual as mulheres saiam para a luta para reivindicar seus direitos. 
Por fim, como uma ramificação da segunda onda, a chamada "terceira onda feminista” centrou-se nas diferenças entre as mulheres e a singularidade de cada experiência. Após um momento inicial no qual apenas mulheres brancas conseguiam reivindicar seus direitos, a ideia de "interseccionalidade" ganha o devido peso e adesão durante os anos 90: é nesse contexto que o movimento finalmente se atenta para a diversidade de etnias, raças e classes sociais que se imbricam com as opressões sofridas pelo grupo. Mulheres não-brancas, queer e que fogem de rótulos socialmente compartilhados ganham papel de destaque e levam as discussóes para um nível maior, no qual a própria ideia universal de "mulher" é problematizada. Como exemplo de seus frutos, podem-se citar obras pós-estruturalistas que hoje são consideradas clássicas para o movimento, como o trabalho pioneiro de Judith Butler acerca da performatividade de gênero e o Manifesto Ciborgue, de Donna Haraway.

Como apontado por Lyrio (2017), o movimento feminista que existe atualmente nas redes sociais não se difere da primeira, segunda e terceira onda somente pelas diferentes demandas da mulher contemporânea. Mais do que isso, "as ferramentas de apoio para lutarem também se atualizaram” (LYRIO, 2000, p. 17). Os debates e mobilizaçóes se apropriam do espaço online e expandem para além do que é produzido pelas integrantes dos coletivos feministas (e femininos). Por meio das caixas de comentários, das campanhas de hashtags e do formato multimídia das redes sociais, mulheres do mundo inteiro compartilham experiências e trocam opiniões, contribuindo assim para uma discussão mais democrática.

Um exemplo das possibilidades geradas pelo uso da Internet é a campanha \#PrimeiroAssédio, promovida pela ONG nacional Think Olga no Twitter em 2015. O coletivo pediu que as seguidoras compartilhassem suas experiências utilizando a hashtag e obteve grande engajamento. Tal ação permitiu que, a partir da análise de mais de três mil mensagens publicadas na rede social, o Think Olga chegasse ao número de 9,7 anos como a idade média das vítimas quando foram assediadas pela primeira vez. Esse mesmo levantamento poderia ter sido feito sem ajuda das redes sociais, mas certamente demandaria uma verba e uma grande disponibilidade de tempo que, muitas vezes, os coletivos não possuem.

Desse modo, Lyrio (2017) sugere que o chamado Feminismo 2.0 seria a "Quarta onda” do movimento, marcado pela utilização das redes sociais por mulheres para produzir conteúdo independente que elas não encontram nas mídias tradicionais. Santini, Terra e Almeida (2016) defendem que os coletivos femininos utilizam as plataformas online como uma

7 Queer é uma expressão em inglês utilizada para se referir a todos os sujeitos que "fogem às regras" tradi cionais de gênero e sexualidade. 
Por uma linguagem mais humana: coletivos ciberfeministas e críticas à abordagem das minorias em notícias na web

ferramenta para romper com a "espiral do silêncio" estabelecida na sociedade. Isso porque as campanhas promovidas nas redes sociais possibilitam que pessoas que não pertencem à mídia tornem públicas questóes privadas, provocando oscilações na opinião dominante, além de contribuírem para a mudança.

Nas últimas décadas, o desenvolvimento da web 2.0 possibilitou que as discussões sociais referentes à problemática dos gêneros construíssem diversas formas de engajamentos ativistas nesse espaço. É nesse lugar, segundo Albu (2017), que os coletivos femininos surgem e, por meio das ferramentas tecnológicas, criam movimentos de resistência numa tentativa de difundir ideais - bem como fomentar agendas feministas que permitam o acesso a uma pluralidade de vozes.

No Brasil, os coletivos femininos são formados principalmente por mulheres jovens que buscam democratizar o acesso à informação, trazendo protagonismo feminino ao jornalismo. Nesse sentido, é interessante observar que esses coletivos se apresentam como portais jornalísticos assumidamente feministas, mesmo que não usem o termo. Além disso, os coletivos também atuam em campanhas que viralizam na internet e promovem conscientização acerca dos problemas enfrentados por mulheres. Como exemplo, em 2018, o coletivo AzMina lançou as campanhas \#CarnavalSemAssédio e \#MamiloLivre nas redes sociais. Além disso, o grupo produz a chamada revista AzMina ${ }^{8}$, publicação online cujo foco é “promover a equidade de gênero por meio da informação e da educação".

Um coletivo bastante popular nas redes é o Valkírias, formado por mulheres que escrevem sobre cultura pop (cinema, música, literatura, games) e oferecem uma ótica feminista acerca dos conteúdos discutidos. A intenção desse coletivo, bem como dos outros, é romper o silêncio sobre algumas temáticas que são ignoradas em mídias mais abrangentes. Já a Agência Patrícia Galvão? é uma instituição que "produz e divulga notícias, dados e conteúdos multimídia sobre os direitos das mulheres brasileiras”. A agência disponibiliza essas notícias tam-

8 Revista digital “AzMina”. Disponível em: https://azmina.com.br/. Acesso em 24 out. 2020.

9 “Agência Patrícia Galvão”. Disponível em: https://agenciapatriciagalvao.org.br/. Acesso em 24 out. 2020. 
bém como sugestóes de pautas para jornalistas que desejam cobrir assuntos relacionados à mulher.

Nessa análise, percebemos que os coletivos propiciam amplo engajamento de usuários pela capacidade de difundir conteúdo e informação para milhares de pessoas ao redor do país. Ao mesmo tempo em que os coletivos versam sobre conteúdos diferentes, a ideia de politizar a igualdade de gênero está presente em todos. Além disso, observamos que a maioria dos coletivos utilizam uma linguagem acessível para que assuntos complexos, como a violência contra a mulher, sejam de fácil compreensão para os leitores. Outro ponto de destaque é a possibilidade de os usuários interagirem nessas plataformas e inclusive contribuírem na produção de conteúdo por meio dos comentários.

\subsection{O Think Olga}

O Think Olga, nosso objeto e guia de estudo para a pesquisa, é uma ONG coletiva feminina de jornalismo criado em 2013 com o objetivo de empoderar mulheres por meio da informação. Através de artigos e cartilhas, ele trata de temáticas como assédio, violência de gênero, disparidade salarial entre homens e mulheres e atua principalmente alinhando assuntos variados como futebol e cinema ao universo feminino.

Além disso, o Think Olga é responsável por diversas campanhas e projetos que visam alertar e conscientizar usuários online sobre questóes ligadas à opressão de gênero. Como exemplo, temos o filme-documentário "Chega de FiuFiu" e as campanhas Olga Esporte Clube $^{10}$, Conexões que salvam ${ }^{11}$, Lista de Mulheres Inspiradoras ${ }^{12}$, Entreviste uma Mulher ${ }^{13}$, entre outras. A ONG também produziu os Minimanuais de Jornalismo Humanizado, que oferecem dicas sobre abordagens a serem evitadas ou seguidas para que jornalistas e veículos não reproduzam preconceitos em suas matérias.

\subsection{Reivindicações}

10 Disponível em: https://thinkolga.com/projetos/olga-esporte-clube/. Acesso em 24 out. 2020.

11 Disponível em: https://www.conexoesquesalvam.com/. Acesso em 24 out. 2020.

12 Disponível em: https://thinkolga.com/2018/01/31/lista-de-mulheres-inspiradoras/. Acesso em 02 jun. 2019.

13 Disponível em: https://thinkolga.com/2018/01/31/entreviste-uma-mulher-1/. Acesso em 02 jun. 2019. 
Por uma linguagem mais humana: coletivos ciberfeministas e críticas à abordagem das minorias em notícias na web

Os coletivos feministas, por meio de suas produçôes e iniciativas (como os Minimanuais do Think Olga utilizados nessa análise), buscam dar voz às mulheres que são silenciadas e mal representadas pela mídia tradicional. Um exemplo notável do resultado dos trabalhos do coletivo em questão é o documentário "Chega de Fiu Fiu”, exibido em várias capitais do Brasil nos meses de maio e junho de 2018.

O filme, que foi financiado coletivamente, utiliza o assédio como tema condutor de uma discussão sobre a exclusão das mulheres nos espaços públicos. A narrativa acompanha três mulheres de diferentes regióes do Brasil e traça um panorama da violência nas cidades. A fim de entender as demandas do público que acompanha o Think Olga, colhemos o depoimento de pessoas que assistiram à estreia do documentário em Belo Horizonte, no Cine Belas Artes.

De modo geral, as pessoas que assistiram ao filme afirmaram que sequer conheciam o Think Olga. No entanto, suas reações ao documentário vão ao encontro dos objetivos do coletivo, que busca dar espaço para debater questóes relacionadas às diferentes violências sofridas pelas minorias no Brasil. Um dos exemplos é Natália (21), estudante de Relações Pú blicas. Ela acredita que quem está por trás das produçôes tem grande influência na maneira como os sujeitos são retratados. Assim, a pequena quantidade de mulheres no Jornalismo seria um fator importante para a existência de narrativas machistas.

Leandro (37), estudante de Geografia, acredita que a mídia camufla a realidade de indivíduos pertencentes a minorias, como negros e transgêneros. Ele afirma que é dada uma maior evidência a pessoas que ocupam posiçôes sociais mais privilegiadas, como o suposto foco em uma mulher branca no caso do documentário em questão. Leandro observa, ainda, que os veículos de comunicação falham ao deixar de mostrar diferentes realidades existentes no Brasil, como foi feito pela obra.

Para Isadora (20), estudante de Engenharia Química, é importante debater esses assuntos, uma vez que eles tendem a ser ignorados, principalmente em áreas do conhecimento que não sejam as ciências humanas. Ela ressalta que as pessoas evitam falar sobre a violência que mulheres e grupos minoritários sofrem, pois tendem a se limitar àquilo que veem na grande mídia.

Mesmo que sob direçôes distintas, portanto, cada comentário registrado durante a sessão fílmica parece indicar certa limitação quanto à visibilidade midiática de membros de grupos minoritários, bem como a crença de que a ausência de mulheres no mercado informativo impossibilita a modificação dos discursos hegemônicos dentro da profissão jornalística. 
Nesse sentido, alguns relatos, como o de Leandro, também ressaltam a importância de se abordar as notícias sob um enfoque interseccional - levando-se em consideração que aspectos como raça e classe influenciam em certas opressóes sofridas pelas minorias, algo que deve, em sua visão, ser fortemente destacado pelos jornalistas. São opiniôes que, embora advindas de pessoas com contextos diferentes, dizem o mesmo: mais do que falar sobre quem sofre, é preciso saber como dizer de seu sofrimento da forma mais humana possível.

\subsection{Minimanual de Jornalismo Humanizado}

No Minimanual de Jornalismo Humanizado, nosso guia de análise, o Think Olga fornece um compilado de erros cometidos em veículos referentes às abordagens escolhidas para retratar os grupos minoritários na mídia. Ainda, a ONG dá dicas de termos apropriados e mais inclusivos para se referir, por exemplo, às pessoas trans, mulheres, pessoas com deficiência ou discorrer sobre temas como aborto e racismo.

Esse manual foi nossa referência para analisar manchetes bem como as escolhas de texto que circulam atualmente em matérias jornalísticas de portais brasileiros. Em especial, iremos dar foco aos manuais que enfatizam a violência contra a mulher e a abordagem LGBT. Por meio do guia, observamos em que medida a linguagem utilizada por esses veículos exclui e reafirma preconceitos ou constrói notícias que sejam respeitosas. Também foi analisado como essa linguagem é distante ou próxima do que os coletivos produzem sobre os grupos minoritários.

Nosso primeiro exercício de análise foi uma reportagem publicada no portal de notícias G1 da Globo. A matéria da manchete "Homem é preso suspeito de pagar R $\$ 10$ para ter relação sexual com menor, em Morrinhos" ${ }^{\prime 1}$, de maio de 2018, parece, num primeiro momento, banalizar e reduzir o problema da exploração sexual. Segundo o minimanual, ao utilizar a expressão "relação sexual” em vez de identificar o assédio e abuso sexual contra uma me-

14 Disponível em https://g1.globo.com/go/goias/noticia/homem-e-preso-suspeito-de-pagar-r-10-parater-relacao-sexual-com-menor-de-15-anos-em-morrinhos.ghtml. Acesso em 20 jun. 2019. 
Por uma linguagem mais humana: coletivos ciberfeministas e críticas à abordagem das minorias em notícias na web

nor, esse tipo de ato passa a ter o mesmo valor e significação das relaçóes sexuais consentidas e apaga a violência do crime.

Outro ponto de destaque levantado pelo Think Olga é a frequência com que as vítimas são desmerecidas e representadas de maneira duvidosa aos leitores. Por exemplo, na reportagem, há a seguinte fala do delegado que investigou o caso: "Ela disse que naquele dia não tinha consumado o ato com ele, mas que já tinham se encontrado antes. Disse que cobrava também de outros homens pelas relaçôes sexuais”. Ou seja, apesar de toda a problemática envolvendo a complexidade da exploração sexual infantil, a matéria preferiu enfatizar características que fazem a vítima ser vista de maneira negativa.

Tais decisões fazem com que a representação da exploração seja diminuída e a matéria não consiga passar aos leitores a dimensão dos problemas do tema. Segundo o Think Olga, uma boa prática jornalística seria desenvolver a notícia e apresentar uma explicação maior sobre o problema. Nesse caso, a reportagem poderia contemplar questóes sobre a exploração infantil no país a fim de informar os leitores.

Ainda se tratando de violência sexual contra a mulher, o minimanual ressalta a importância de utilizar o termo "estupro" quando não há uma relação de consentimento. Segundo a publicação, "quando a especificação do abuso sexual for extremamente necessária, (deve-se) utilizar os termos estupro anal, estupro oral e estupro vaginal, abolindo a associação dessas práticas com o sexo consensual via ânus, boca ou vagina” (THINK OLGA, 2017).

No resumo sobre os principais casos de assédio de Hollywood disponível na reportagem "Morgan Freeman é acusado de assédio, diz publicação" 15 , do portal da Folha de São Paulo, também de maio de 2018, um estupro oral do qual o diretor Brett Ratner é acusa do é definido como "sexo oral forçado". Segundo o minimanual, ao evitar a palavra estupro, a atitude do acusado é suavizada.

O minimanual sobre cidadania de pessoas LGBT ressalta a importância de utilizar os termos corretos para se referir a esses indivíduos. É notável que grande parte dos jornalistas tem dificuldade ao tratar do assunto, o que acaba por dificultar o entendimento de notícias que falem sobre transexuais, por exemplo. Uma matéria que chamou a atenção pela utilização incorreta dos termos é "TSE definirá se cota de mulher inclui transexual” ${ }^{16}$, do site Esta-

15 Disponível em https://www1.folha.uol.com.br/ilustrada/2018/05/morgan-freeman-e-acusado-deassedio-diz-publicacao.shtml. Acesso em 20 jun. 2019.

16 Disponível em https://politica.estadao.com.br/blogs/coluna-do-estadao/tse-definira-se-cota-demulher-inclui-transexual/. Acesso em 20 jun. 2019. 
dão. De dezembro de 2017, a notícia, que se referia à possibilidade do Tribunal Superior Eleitoral aceitar mulheres transexuais na cota feminina dos partidos, erra ao dizer que "a Corte Eleitoral deve definir, por exemplo, se um homem transexual que disputar a próxima campanha pode ser incluído pelos partidos na cota feminina”. Se referir a mulheres transexuais como homens reforça noções incorretas sobre as identidades desse grupo e causa desinformação, visto que o texto também não deixa claro para o leitor aquilo que tenta noticiar.

De acordo com esse mesmo manual, a invisibilidade lésbica é um dos grandes problemas da sociedade que reverberam no fazer jornalístico. Na reportagem de março de 2018 “Companheira de Marielle permanece 7 horas na Delegacia de Homicídios para depoimento" ${ }^{17}$ do portal de notícias UOL, Mônica Benício é retratada como companheira de Marielle ao invés do seu verdadeiro status de namorada à época. Em matérias que retratam casais heterossexuais, o termo "companheira" é inutilizado na maioria dos casos, mas em reportagens que versam sobre a comunidade LGBT o termo é frequente e apaga sinais da verdadeira relação. Mônica e Marielle moravam juntas há muitos anos, mas muitas reportagens preferiram não enfatizar que a vereadora e sua esposa eram um casal lésbico, abordando essa questão somente superficialmente. Nesta matéria, apesar do título apontar para um texto que fale sobre a esposa de Marielle, o conteúdo prova o contrário: a principal voz ouvida é de Marcelo Freixo, Mônica sequer é representada por uma fala na reportagem. Tal invisibilidade demonstra como os veículos não estão preparados para abordar notícias em que as fontes fujam do padrão heteronormativo, seja por desconhecimento de termos adequados ou por medo de "chocar" os leitores.

Em contrapartida, os minimanuais do Think Olga oferecem algumas dicas de boas práticas ${ }^{18}$ a serem utilizadas no fazer jornalístico. Tais dicas reúnem termos e abordagens que podem substituir os velhos preconceitos que dominam a escrita de muitas matérias. Por exemplo, na reportagem de maio de 2018 "Estudante trans desaparecida no RJ foi assassinada, diz família"19 ${ }^{19}$ da Folha de São Paulo, a jovem trans é retratada pelo gênero que se identificava, além de ser apresentada como Matheusa, seu nome social. A matéria respeitou a vítima e ainda divulgou dados sobre o alto índice de agressóes sofridos por pessoas trans. Ainda, a repor-

17 Disponível em https://noticias.uol.com.br/cotidiano/ultimas-noticias/2018/03/20/muito-abaladacompanheira-de-marielle-depoe-na-delegacia-de-homicidios.htm. Acesso em 20 jun. 2019.

18 Disponível em https://thinkolga.com/2018/01/31/minimanual-de-jornalismo-humanizado/. Acesso em 20 jun. 2019.

19 Disponível em https://www1.folha.uol.com.br/cotidiano/2018/05/estudante-trans-desaparecida-norj-foi-assassinada-diz-familia.shtml. Acesso em 20 jun. 2019. 
Por uma linguagem mais humana: coletivos ciberfeministas e críticas à abordagem das minorias em notícias na web

tagem evocou a voz de familiares, pessoas próximas e da universidade em que a vítima estudava para reforçar que uma pessoa trans não difere das demais. Tais aspectos revelam que, na construção de uma notícia, pode-se dar informação sem ferir ou diminuir os grupos minoritários.

5

\section{CONCLUSÃO}

A presença de mulheres no jornalismo e na mídia brasileira como um todo tem, historicamente, forte ligação com o movimento feminista. Desde as publicações impressas do século passado, como a Brasil Mulher e a Nós Mulheres, até os coletivos feministas da web 2.0, como o AzMina e o Think Olga, os movimentos sociais têm se apropriado das ferramentas midiáticas para reivindicarem direitos e compartilharem ideias. Em contrapartida, inúmeros materiais jornalísticos, como os analisados ao longo do trabalho, seguem atuando no reforço de certos estigmas acerca de membros de grupos minoritários. Ao trabalharmos com reportagens produzidas tanto por homens quanto por mulheres, deixamos claro que a reprodução do preconceito independe do gênero de quem escreve - o que aponta para a necessidade geral de se humanizar o modo como se fala no outro.

Vale ressaltar que as redes sociais possibilitam que o debate sobre assuntos relacionados a grupos minoritários (mulheres, pessoas LGBT, pessoas negras e pessoas com deficiência, por exemplo) seja realizado com a contribuição de indivíduos de diferentes realidades. Além disso, o fácil acesso à internet permite que as próprias minorias criem um conteúdo que as representem adequadamente, como é o caso do Think Olga e demais iniciativas. Tais produções nos ajudam a repensar o jornalismo tradicional e questionar estereótipos que há tempos são perpetuados. Os Minimanuais de Jornalismo Humanizado mostram que ainda existem vários vícios de linguagem e falta de conhecimento por parte dos produtores de notícia. No entanto, também apontam um caminho que, com um pouco de esforço, pode fazer com que os jornalistas repensem a forma como retratam indivíduos minorizados.

Bons exemplos que já são vistos na mídia hegemônica são a prova de que é possível atingir uma mudança que pode influenciar positivamente muitos grupos que tendem a ser marginalizados e apagados nas produções jornalísticas. Promover novas maneiras de representá-los é, além de respeitar sua existência, uma forma de combater preconceitos enraizados 
Helvio de Araújo Caldeira Júnior, Luíza Martins dos Santos, Stéphani Júlia Sales Leite

na sociedade, uma vez que o jornalismo tradicional é, mais que mera parte da formação da opinião pública, um configurador da própria cultura dos povos. 
Por uma linguagem mais humana: coletivos ciberfeministas e críticas à abordagem das minorias em notícias na web

\section{REFERÊNCIAS BIBLIOGRÁFICAS}

ALBU, D. Ciberfeminismo no Brasil: construindo identidades dentro dos limites da rede. In: 11 SEMINÁRIO INTERNACIONAL FAZENDO GÊNERO E 13 CONGRESSO MUNDOS DE MULHERES, FLORIANÓPOLIS, 2017.

ARAÚJO, M. P. N. A utopia fragmentada: as novas esquerdas no Brasil e no mundo na década de 1970. Rio de Janeiro: Editora FGV, 2000.

CESTARI, M. J. Imprensa Feminista Brasileira na década de 1970: um lugar de enunciação público e legítimo das mulheres. Língua, literatura e ensino (UNICAMP), v. 03, p. 107-116, 2008.

FREITAS, V. G. O Jornal Mulherio e sua agenda feminista: primeiras reflexóes à luz da teoria política feminista. História, histórias, Brasília, v. 2, n. 4, 2014.

LEITE, R. S. C. Brasil Mulher e Nós Mulheres: origens da imprensa feminista no Brasil. Revista Estudos Feministas, Florianópolis, v. 11, n. 1, 2003.

LYRIO, C. R. H. Feminismo e redes sociais: produção de informação no site "Think Olga". Universidade Federal Fluminense. Rio de Janeiro: 2017.

Minimanuais de Jornalismo Humanizado: Parte I a VI. Think Olga, 2017. Disponível em: https://issuu.com/thinkolga. Acesso em: 01 jun. 2019.

PARK, R. E. A notícia como forma de conhecimento. In: STEINBERG, Charles S. (Org). Meios de Comunicação de Massa, São Paulo: Cultrix, [1940]1970.

SAFFIOTI, H. B. Feminismos e seus frutos no Brasil. In: SADER, E. (Org.). Movimentos sociais na transição democrática. São Paulo: Cortez, 1986. 
Helvio de Araújo Caldeira Júnior, Luíza Martins dos Santos, Stéphani Júlia Sales Leite

SANTINI, R. M.; TERRA, C.; ALMEIDA, A. R. D. Feminismo 2.0: A mobilização das mulheres no Brasil contra o assédio sexual através das mídias sociais (\#primeiroassedio). P2P Inovação, v. 3, p. 148-164, 2016. 